\title{
Detection of Noncovalent FKBP-FK506 and FKBP-Rapamycin Complexes by Capillary Electrophoresis-Mass Spectrometry and Capillary Electrophoresis-Tandem Mass Spectrometry
}

\author{
Yin-Liang Hsieh, ${ }^{*}$ Jianyi Cai, Yu-Tsyr Li, and Jack D. Henion \\ Analytical Toxicology, Cornell University, Ithaca, New York, USA \\ Bruce Ganem \\ Department of Chemistry, Baker Laboratory, Cornell University, Ithaca, New York, USA
}

\begin{abstract}
The well known biospecific noncovalent receptor-ligand association complexes between the immunophilin FKBP and the immunosuppressive drugs FK506 and Rapamycin (RM) were investigated by on-line capillary electrophoresis-mass spectrometry (CE-MS) under selected ion monitoring (SIM) conditions and by CE-MS with tandem mass spectrometry (CE-MS/MS) under selected reaction monitoring (SRM) conditions. Solutions of hFKBP $(33.3 \mu \mathrm{M})$ were dissolved in $50 \mathrm{mM}$ ammonium acetate at pH 7.5. Samples that contained $100 \mu \mathrm{M}$ of FK506 or RM also were prepared under the same solution conditions. By using these aqueous $\mathrm{pH}$ neutral conditions, samples were analyzed by SIM CE-MS and SRM CE-MS and the target complexes were separated by $\mathrm{CE}$ with mass spectrometer detection of the individual complexes between FKBP and FK506 $[\mathrm{hFKBP}+\mathrm{FK} 506+7 \mathrm{H}]^{7+}$ as well as FKBP and RM $[\mathrm{hFKBP}+\mathrm{RM}+7 \mathrm{H}]^{7+}$. In an experiment where a mixture of FK506 and RM was analyzed in the presence of FKBP, a nine-to-one ratio of ion current abundances between the RM and FK506 complexes was observed as reported in the literature from other studies. These results suggest that CE-MS and CE-MS/MS may be yet another analytical method for studying noncovalent interactions of biologically important macromolecules under physiological conditions. (J Am Soc Mass Spectrom 1995, 6, 85-90)
\end{abstract}

$\mathrm{I}$ n 1991, we reported the first use of ion spray mass spectrometry to obtain mass spectral data for noncovalent receptor-ligand association complexes of the immunophilin FKBP with the immunosuppressive drug FK506 and a related ligand, Rapamycin (RM), under physiological conditions [1]. Since then, we [2-10] and others [11-19] have shown that ion spray mass spectrometry and tandem mass spectrometry can detect noncovalent complex formation and measure binding affinities in biological systems.

The immunophilin FKBP is known to function as a peptidyl-prolyl cytosolic rotamase whose activity is inhibited by binding of FK506 and Rapamycin (RM) [20-25] (see Figure 1 for the structures of FK506 and RM). The immunophilin has a higher affinity at $\mathrm{pH} 7.8$ for $\mathrm{RM}\left(K_{\mathrm{i}}=0.2 \mathrm{nM}\right)$ than for FK506 $\left(K_{\mathrm{i}}=1.7 \mathrm{nM}\right)$ [26]. The FKBP-FK506 complex disrupts calcium-

Address reprint requests to Dr. Jack D. Henion, Analytical Toxicology, 927 Warren Drive, Ithaca, New York 14850.

*Current address: PerSeptive Biosystems, Inc., 38 Sidney St., Cambridge, MA 02139 dependent binding to the protein phosphatase calcineurin, whereas the FKBP-RM complex blocks a family of calcium-independent signaling pathways triggered by ribosomal kinases.

As a bioanalytical technique [27-33], the coupling of capillary electrophoresis (CE) to mass spectrometry promises to provide an excellent method for identification of biomolecular interactions. When performed in the selected ion monitoring (SIM) mode, capillary electrophoresis-mass spectrometry (CE-MS) also can provide excellent sensitivity and specificity for detection of trace analytes at low levels in highly aqueous buffered conditions [31]. With its high separation efficiency and orthogonal separation mechanism, CE-MS promises to be a useful analytical technique for biochemical and biomedical research. In this article we expand our earlier studies on the analysis of immunophilin complexes by ion spray mass spectrometry to include studies of the noncovalent interactions of FK506 and RM with human FKBP (hFKBP) by CE-MS and CE-MS coupled with tandem mass spectrometry (CE-MS/MS). 
FK506

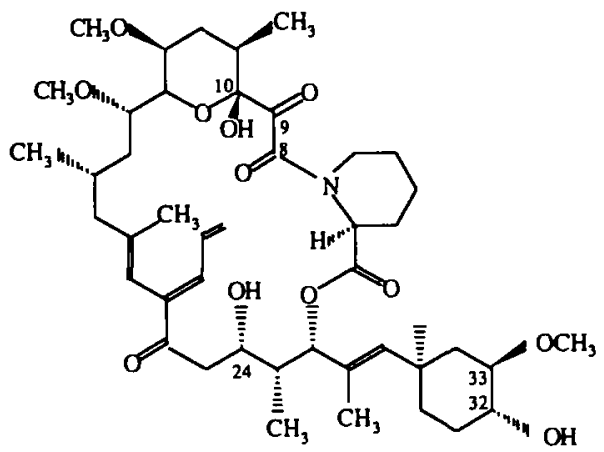

MW = 804 Da
Rapamycin



$\mathrm{MW}=913 \mathrm{Da}$

Figure 1. Structures for FK506 and RM.

\section{Experimental}

Cloned, overexpressed human FKBP [24] was purified in our laboratory. Samples of FK506 and RM were supplied by Professor J. Clardy (Department of Chemistry, Cornell University) and Wyeth-Ayerst Research (Princeton, NJ), respectively. A solution of hFKBP (33.3 $\mu \mathrm{M})$ was dissolved hFKBP in $50-\mathrm{mM}$ ammonium acetate at $\mathrm{pH}$ 7.5. Samples that contained $100 \mu \mathrm{M}$ of FK506 or RM also were prepared under the same solution conditions. Samples of hFKBP were mixed with FK506 and RM ( 25 to $40 \mu \mathrm{M}$ ) at ambient temperature with $25 \%$ methanol for continuous infusion sample introduction as well as CE-MS binding studies.

\section{Conditions for Mass Spectrometry}

A Sciex TAGA 6000E atmospheric pressure ionization (API) triple quadrupole mass spectrometer (Sciex, Thornhill, Ontario) upgraded to an API-III with a scan range from $m / z 10-2400$ was used for all experiments. Samples were continuously introduced at $2 \mu \mathrm{L} / \mathrm{min}$ at ambient temperature by an infusion pump (Harvard Apparatus, South Natick, MA) for mass spectrometry experiments. Full-scan mass spectra were acquired in the multichannel analyzer mode (sum of 16 scans) with a step size of $0.5 \mathrm{u}$ and an acquisition time of $3 \mathrm{~s}$ per scan. The ion spray probe tip was positioned approximately $1 \mathrm{~cm}$ off-axis and $1 \mathrm{~cm}$ away from the ion sampling orifice and maintained at $4.5 \mathrm{kV}$ with a flow of liquid nitrogen blow-off nebulizing gas maintained at $45 \mathrm{lb} /$ in. $^{2}$. Polypropylene glycol in $4: 1 \mathrm{CH}_{3} \mathrm{CN} / \mathrm{H}_{2} \mathrm{O}$ (3-mM NH${ }_{4} \mathrm{OAC}$ ) was used for tuning and mass axis calibration for each mass-resolving quadrupole $\left(Q_{1}\right.$ and $\mathrm{Q}_{3}$ ). Single mass spectrometry (full scan) and electropherograms were performed at declustering potentials of $30 \mathrm{~V}$ in the positive ion mode of detection. All CE-MS experiments were carried out in the SIM mode with the standard PE-Sciex Macintosh-based software. In the $\mathrm{CE}$-tandem mass spectrometry (CE-
MS/MS) experiments, argon collision gas was introduced into the collision cell (Q2) with a collision gas thickness of $2 \times 10^{14}$ atoms $/ \mathrm{cm}^{2}$.

\section{Conditions for Capillary \\ Electrophoresis-Mass Spectronetry}

A high-performance capillary electrophoretic system (model P/ACE 2050, Beckman Instruments, Inc., Palo Alto, CA) was used in this study. Separation was performed on an uncoated $50-\mu \mathrm{m}$ i.d. $\times 110-\mathrm{cm}$ fusedsilica capillary (Polymicro Technologies, Phoenix, AZ). The in-house ion spray interface shown in Figure 2 consists of three concentric capillaries that introduce a sheath liquid flow and nebulizing gas. The sheath liquid flow was composed of $80 \% \mathrm{CH}_{3} \mathrm{CN}$ and $20 \%$ $5-\mathrm{mM} \mathrm{NH}_{4} \mathrm{OAc}$ at $\mathrm{pH} 7.5$ and was delivered at 2 $\mu \mathrm{L} / \mathrm{min}$ by an infusion pump (Harvard Apparatus, South Natick, MA). The three concentric capillaries were coupled with the two tees for separate but simultaneous introduction of the sheath liquid flow and the nitrogen nebulizing gas. This approach afforded a straightforward robust CE-MS interface for carrying out the described experiments. The experiments described were routinely performed by positioning the concentric capillaries at the tip as shown in Figure 2 and by optimizing the flow of sheath liquid and nitrogen nebulizing gas.

The capillary electrophoretic separation was accomplished by applying $30 \mathrm{kV}$ at the anode while $4.5 \mathrm{kV}$ was applied to the cathode via the ion spray interface high voltage supply which resulted in a potential difference across the CE capillary of $25.5 \mathrm{kV}$. Samples were loaded into the anode of the capillary via a 25-s pressure injection. Sample loading into the CE capillary was performed $(50-\mu \mathrm{M}$ hFKBP with $50-\mu \mathrm{M}$ FK506 and $50-\mu \mathrm{M} R \mathrm{R}$, respectively) by using the standard pressure injection technique incorporated in the Beckman P/ACE 2050 capillary electrophoresis system used in this work. 


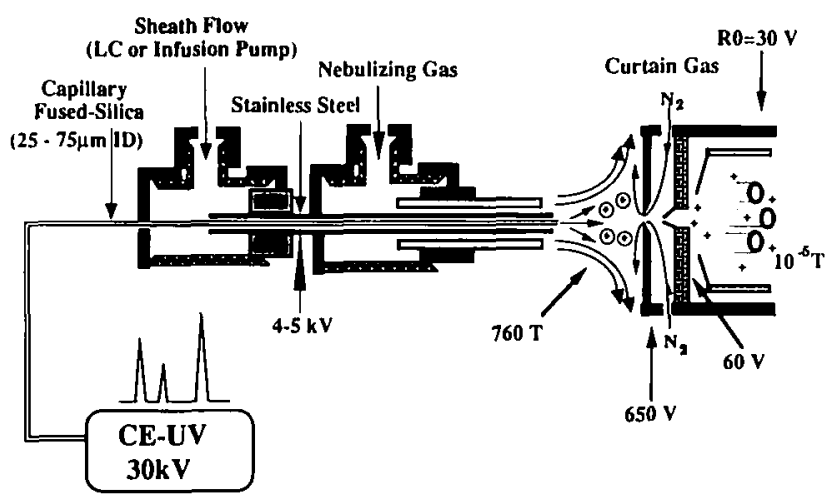

Figure 2. Ion spray CE-MS interface equipped with a sheath flow coupling.

All buffer, immunophilin, and ligand solutions were prepared fresh daily and filtered through $0.45-\mu \mathrm{m}$ nylon-66 syringe filters (Rainin, Woburn, MA) before use.

\section{Results and Discussion}

The cis-trans peptidyl-prolyl isomerase hFKBP is known to bind with high specificity to FK506 [23-25] and RM $[34,35]$. To expand earlier studies on the analysis of immunophilin complexes by ion spray mass spectrometry, we have employed CE-MS and CEMS/MS to characterize specific noncovalent interactions and to assay competitive binding affinities between the receptor protein hFKBP and its ligands FK506 or RM.

\section{Detection of Noncovalent hFKBP-FK506 Complexes by Capillary Electrophoresis-Mass Spectrometry and Capillary Electrophoresis-Tandem Mass Spectrometry}

In competitive binding studies with equimolar concentrations of FK506 and RM, the ion spray mass spectrum of the hFKBP-RM complex exhibited a ninefold greater ion current signal than did the hFKBP-FK506 complex. These findings were consistent with an approximate ninefold difference in $K_{i}$ values for the two ligands [34,35]. To determine whether the noncovalent complexes could be separated by CE, on-line CE-MS was used under physiological-like conditions (50-mM $\mathrm{NH}_{4} \mathrm{OAc}, \mathrm{pH}=7.5$ ). Figure 3 displays the SIM CE-MS electropherogram of hFKBP at $m / z 1689.0$, detected by using an uncoated $50-\mu \mathrm{m}$ i.d. $\times 110-\mathrm{mm}$ fused-silica capillary column in $50-\mathrm{mM} \mathrm{NH}_{4} \mathrm{OAc}$ electrolyte at $\mathrm{pH}$ 7.5. Two slightly different migration times of hFKBP at $m / z 1689.0$ were observed, which suggested the presence of two discrete conformations or folded states of hFKBP in solution. Interestingly, the two hFKBP conformations could not be detected under normal infusion mass spectrometry conditions.

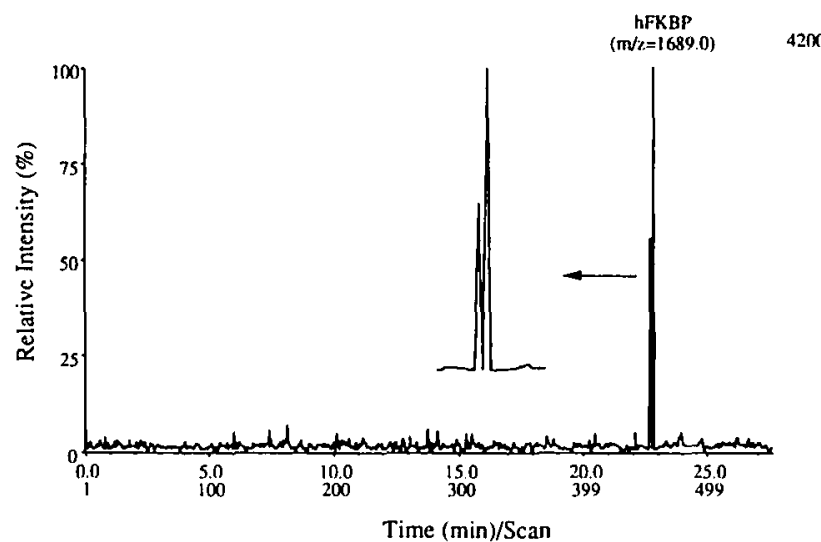

Figure 3. SIM CE-MS electropherogram of hFKBP at $m /=1689.0$ separated and detected by using an uncoated $50-\mu \mathrm{m}$ i.d. $\times 110$ $\mathrm{mm}$ fused-silica capillary column in 50 - $\mathrm{mM} \mathrm{NH}_{4} \mathrm{OAc}$ electrolyte at $\mathrm{pH} 7.5$

The SIM CE-MS electropherogram for ions at $m / z$ $1689.0\left(\right.$ hFKBP at $7^{+}$) and $m / z 1804.5$ (hFKBP + FK506 at $7^{+}$) is shown in Figure 4. These ions were chosen because they represent the base peaks of these compounds [2] and thus provide the highest sensitivity in these experiments. In a mixture that contained $50-\mu \mathrm{M}$ hFKBP and $100-\mu \mathrm{M}$ FK506, the noncovalent hFKBP-FK506 complex was resolved readily from the uncomplexed hFKBP at $\mathrm{pH} 7.5$ (Figure 4). Moreover, the additional electropherogram peaks labeled in Figure 4 indicated that both conformations of hFKBP were capable of binding to FK506. Thus, CE-MS appears to provide an alternative technique to liquid chromatography-mass spectrometry for the study of weak, noncovalent interactions between a receptor and its ligand. The solution characteristics common to capillary electrophoresis described in this article appear to offer favorable conditions for the formation and detection by SIM CE-MS of these interesting noncovalent species.

A direct method for determination of immunophilin-ligand complex formation via CE-MS/MS also was developed. The method involved collision-

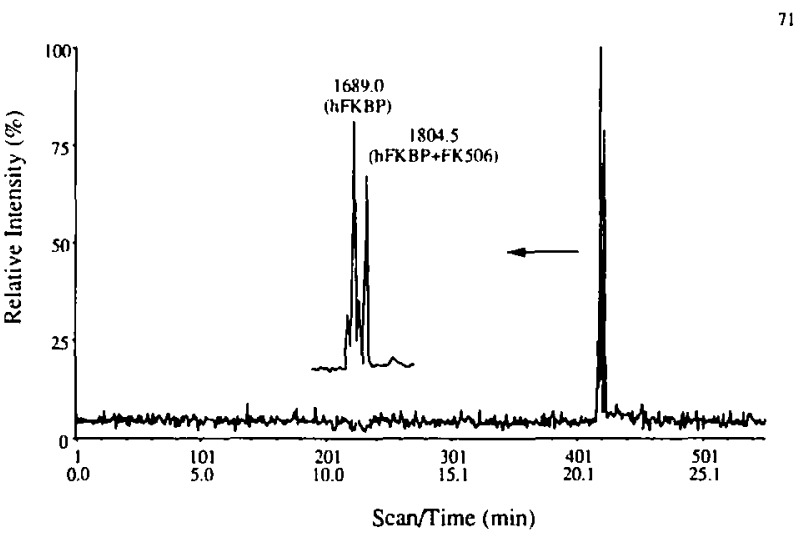

Figure 4. SIM CE-MS electropherogram of hFKBP at $m / z 1689.0$ and $h F K B P-F K 506$ at $m / z 1804.5$, detected by using an uncoated $50-\mu \mathrm{m}$ i.d. $\times 110-\mathrm{cm}$ fused-silica capillary column in $50-\mu \mathrm{M}$ $\mathrm{NH}_{4} \mathrm{OAc}$ electrolyte at $\mathrm{pH}$ 7.5. The inset is an expansion of the ion current electropherogram. 
induced dissociation of the most abundant noncovalent complex ion $[\mathrm{hFKBP}+\mathrm{FK} 506+7 \mathrm{H}]^{7+}$ at $m /=$ 1804.5 under conditions of constant collision energy $(420 \mathrm{eV})$ and collision gas thickness $\left(2 \times 10^{14}\right.$ atoms $/ \mathrm{cm}^{2}$ ). In the resulting CE-MS/MS experiments carried out with selected reaction monitoring (SRM), the summed precursor and product ions $(m / z 1804.5$ and 1689.0 , respectively) afforded the electropherogram shown in Figure 5. The principal product ion electropherogram displayed mass-to-charge ratio values that correspond to the expected $[\mathrm{hFKBP}+7 \mathrm{H}]^{7}$ at $m / z$ 1689.0. Moreover, two different conformations of noncovalent hFKBP-FK506 complexes also were evident in this CE-MS/MS electropherogram. An additional potential future benefit of these CE-MS/MS experiments could be the determination of the relative strengths of the interactions between these noncovalent species.

\section{Detection of Noncozalent hFKBP-RM Complexes} by Capillary Electrophoresis-Mass Spectrometry and Capillary Electrophoresis-Tandem

\section{Mass Spectrometry}

The CE-MS electropherogram (Figure 6) of a mixture of hFKBP $(50 \mu \mathrm{M})$ and $\mathrm{RM}(100 \mu \mathrm{M})$ paralleled earlier mass spectrometry studies [1], which again indicated that RM bound more avidly to hFKBP than did FK506. With RM, only a single hFKBP complex was observed, contrary to earlier results with FK506. To confirm the noncovalent nature of the complex as [hFKBP $+\mathrm{RM}+$ $7 \mathrm{H}]^{7+}$, the precursor ion complex at $m / z 1820.0$ was subjected to CE-MS/MS conditions (Figure $7 a$ and $b$ ). The SRM CE-MS electropherogram shown in Figure 7a was obtained by dissociation and monitoring of the noncovalent hFKBP-RM complex at $m / z 1820.0$ to the dissociation product ion hFKBP at $m / z$ 1689.0. Figure $7 \mathrm{~b}$ shows the SRM CE-MS ion current electropherogram for both the noncovalent hFKBP-RM complex

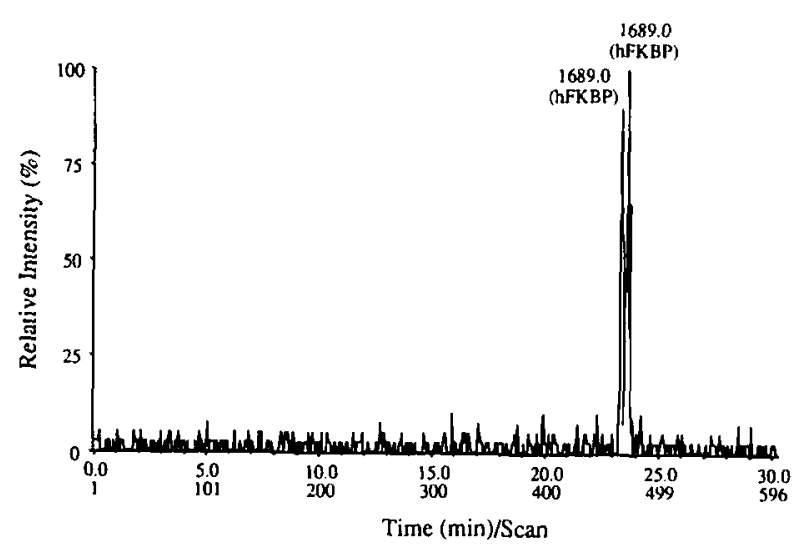

Figure 5. SRM CE-MS electropherogram of noncovalent hFKBP-FK506 complex at $m / z 1804.5$ and hFKBP at $m / z 1689.0$ detected by using an uncoated $50-\mu \mathrm{m}$ i.d. $\times 110-\mathrm{cm}$ fused-silica capillary column in $50-\mathrm{mM} \mathrm{NH}_{\downarrow} \mathrm{OAc}$ electrolyte $(\mathrm{pH} 7.5)$ at 420 eV.

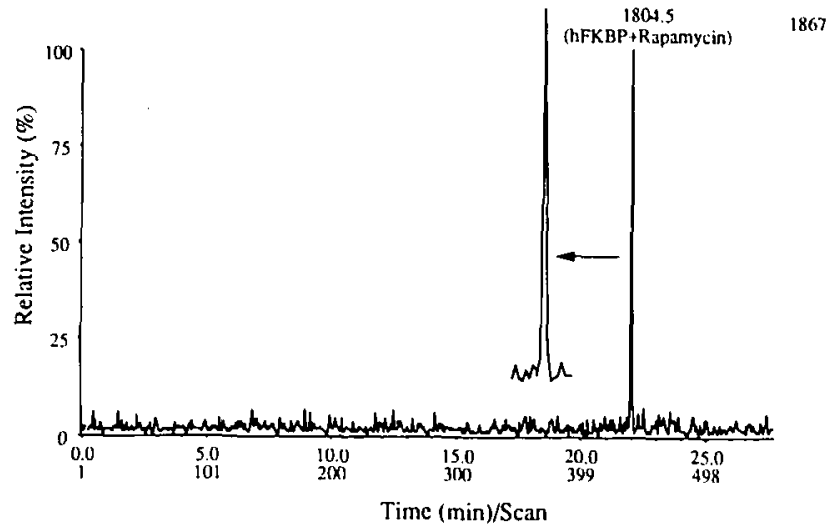

Figure 6. SIM CE-MS electropherogram of $h F K B P$ at $m /=1689.0$ and $\mathrm{hFKBP}-\mathrm{RM}$ at $m /=1820.0$ detected by using an uncoated $50-\mu \mathrm{m}$ i.d. $\times 110-\mathrm{mm}$ fused-silica capillary column in $50-\mathrm{mM}$ $\mathrm{NH}_{4} \mathrm{OAc}$ electrolyte at $\mathrm{pH} 7.5$. The inset is an expansion of the ion current electropherogram.

a

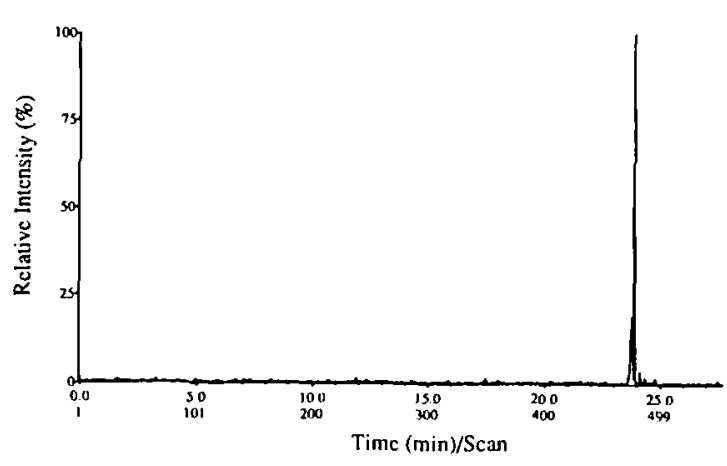

b

1820.0 (h-KMP+RM) / 1689.0 (h/:KBP)

480

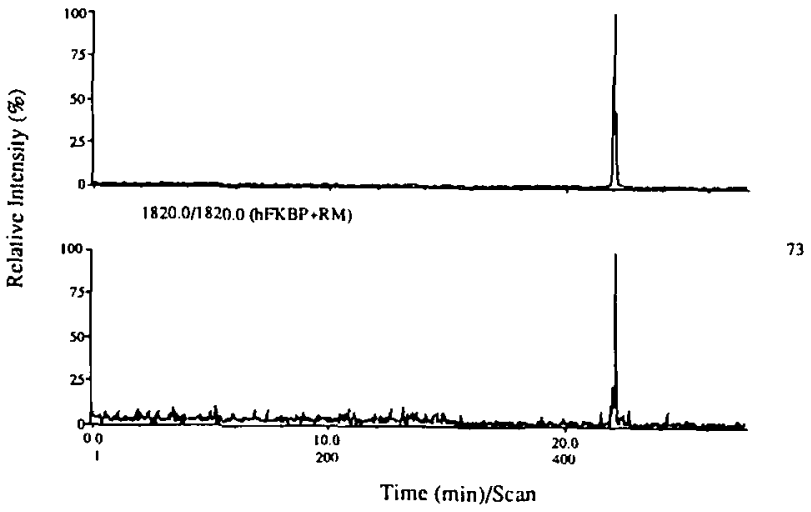

Figure 7. (a) SRM CE-MS total ion current electropherogram of noncovalent hFKBP-RM complex at $m / z 1820.0$ and its product ion $\mathrm{hFKBP}$ at $m / z$ 1689.0. (b) Individual SRM CE-MS extracted ion electropherograms of the noncovalent hFKBP-RM complex at $m / z 1820.0$ and hFKBP at $m / z 1689.0$ detected by using an uncoated $50-\mu \mathrm{m}$ i.d. $\times 110-\mathrm{cm}$ fused-silica capillary column in $50-\mathrm{mM} \mathrm{NH}_{+} \mathrm{OAc}$ electrolyte ( $\mathrm{pH} 7.5$ ) at $420 \mathrm{eV}$. 
precursor ion at $m / z 1820.0$ and its product ion hFKBP at $m / z 1689.0$.

\section{Monitoring Competitive Binding of hFKBP with FK506 and RM by Using Capillary Electrophoresis-Mass Spectrometry}

In competition binding experiments between hFKBP and equimolar amounts of FK506 and RM (Figure 8a and b), CE-MS analyses displayed results consistent with previous mass spectrometry studies, which indicate that the ion current signal of the hFKBP-RM complex is approximately ninefold more abundant than the hFKBP-FK506 complex. This increase is reflected by the different ion current abundances observed in the upper and lower CE-MS electropherograms shown in Figure $8 \mathrm{~b}$ for $m / z 1804.5[\mathrm{hFKBP}+\mathrm{FK} 506+7 \mathrm{H}]^{7+}$

a

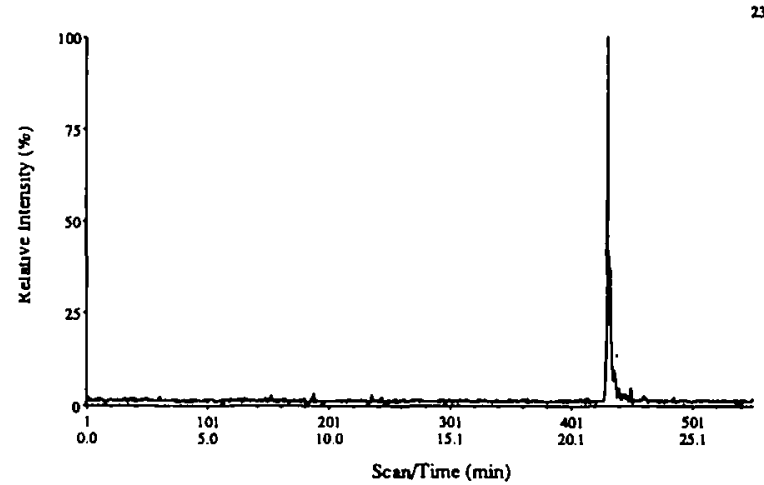

b

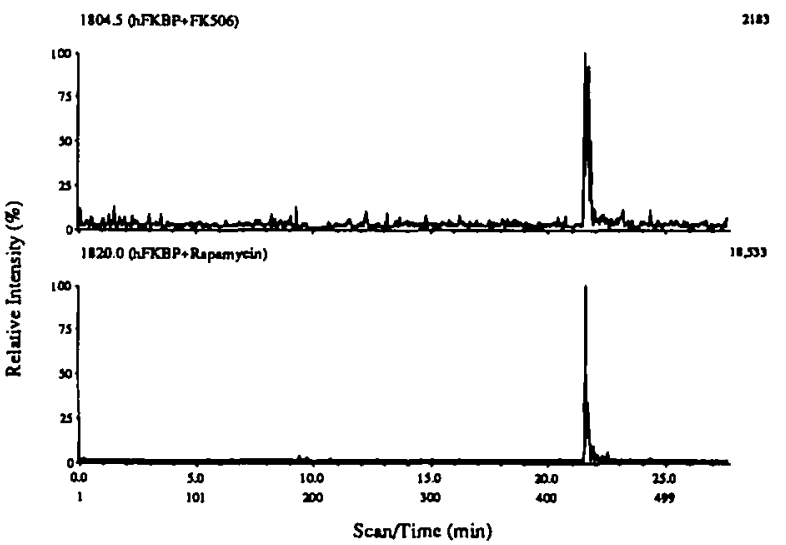

Figure 8. Competition binding (a) SIM CE-MS electropherogram of $40-\mu \mathrm{M}$ FK506 and $40-\mu \mathrm{M}$ RM with $25-\mu \mathrm{M}$ hFKBP and (b) SIM CE-MS extract electropherogram of 40- $\mu \mathrm{M}$ FK506 and 40- $\mu \mathrm{M}$ RM with $25-\mu \mathrm{M}$ hFKBP detected by using an uncoated $50-\mu \mathrm{m}$ i.d. $\times 110-\mathrm{cm}$ fused-silica capillary column in $50-\mathrm{mM}$ $\mathrm{NH}_{4} \mathrm{OAc}$ electrolyte ( $\mathrm{pH} 7.5$ ).
(2183 counts) and $m / z 1820.0[\text { hFKBP }+\mathrm{RM}+7 \mathrm{H}]^{7+}$ $(18,533$ counts), respectively.

\section{Conclusions}

Studies from several groups [1-19] have shown that biologically important noncovalent complexes may be detected by electrospray mass spectrometry. A recent report [36] describes the determination of binding constants of ligands to proteins by affinity $C E$, which further substantiates the potential analytical potential of CE for such studies. In the current study, CE-MS and CE-MS/MS were used to detect such species and to explore the relative binding affinity and inhibitory effects of the noncovalent immunophilin (hFKBP) ligands (FK506 and RM) complexes with high sensitivity and resolution. Thus CE-MS and CE-MS/MS may find application in assaying certain host-guest complexation. These techniques provide yet another analytical method for the study of noncovalent interactions of biologically important macromolecules under physiological conditions.

\section{Acknowledgment}

Generous financial support was provided from the National Institutes of Health (Grant GM 47931).

\section{References}

1. Ganem, B.; Li, Y. T.; Henion, J. D. I. Am. Chem. Soc. 1991, $113,6294$.

2. Ganem, B.; Li, Y. T.; Henion, J. D. J. Am. Chem. Soc. 1991, $113,7818$.

3. Ganem, B.; Li, Y.-T.; Henion, J. D. Tetrahedron Lett. 1993, 34 , 1445.

4. Li, Y.-T.; Hsieh, Y.-L.; Henion, J. D.; Ganem, B. J. Am. Soc. Mass Spectrom. 1993, 4, 631.

5. Li, Y.-T.; Hsieh, Y.-L.; Henion, J. D.; Ganem, B.; Senko, M. W.; McLafferty, F. W. J. Am. Chem. Soc. 1993, 34, 1445.

6. Ganem, B.; Henion, J. D. Chemtracts 1993, 6, 1 (review).

7. Hsieh, Y. L.; Li,Y.-T.; Henion, J. D.; Ganem, B. Biol. Mass Spectrom. 1994, 23, 272.

8. Ganem, B.; Li, Y. T.; Hsieh, Y. L.; Henion, J. D.; Kabood, B. F.; Frey, M. W.; Benkovic, S. J. J. Am. Chem. Soc, 1994, 116, 1352.

9. Lim, H. K.; Hsieh, Y. L.; Ganem, B.; Henion, J. D. I. Mass Spectrom. 1994, submitted.

10. Li, Y. T.; Hsieh, Y. L.; Ocain, T. D.; Schiehser, G. A.; Ganem, B.; Henion, J. D. J. Am. Chem. Soc. 1994, 116, 1487.

11. Baca, M.; Kent, B. H. J. Am. Chem. Soc. 1992, 114, 3992.

12. Ganguly, A. K.; Pramanik, B. N.; Tsarbopoulos, A.; Covey, T. R.; Huang, E.; Fuhrman, S. A. J. Am. Chem. Soc. 1992, 114, 6559.

13. Goodlett, D. R.; Camp, D. G., II; Hardin, C. C.; Corregan, M.; Smith, R. D. Biol. Mass Spectrom. 1993, 22, 181.

14. Huang, E. C.; Pramanik, B. N.; Tsarbopoulos, A.; Reichert, P.; Ganguly, A. K.; Trotta, P. P.; Nagabhushan, T. L.; Covey, T. R. J. Am. Soc. Mass Spectrom. 1993, 4, 624.

15. Jaquinod, M.; Leize, E.; Potier, N.; Albrecht, A.-M.; Shanzer, A.; Dorsselaer, A. V. Tetrahedron Lett. 1993, 34, 2771.

16. Light-Wahl, K. J.; Springer, D. L.; Winger, B. E.; Edmonds, C. G.; Camp, D.G., II; Thrall, B. D.; Smith, R. D. J. Am. Chem. Soc. 1993, 115, 803. 
17. (a) McNeal, C. J., Ed. The Analysis of Peptides and Proteins by Mass Spectrometry; Wiley: New York, 1988; (b) Biemann, K. Biomed. Environ. Mass Spectrom. 1988, 16, 99; (c) Martin, S. A.; Biemann, K. Int. I. Mass Spectrom. Ion Processes 1987, 78, 213; (d) Gaskell, S. J., Ed. Mass Spectrometry in Biomedical Resemrch; Wiley: New York, 1986.

18. Ogorzalek Loo, R. R.; Goodlett, D. R.; Smith, R. D.; Loo, J. A 1. Am. Clem. Soc. 1993, 115, 4391.

19. Smith, R. D.; Light-Wahl, K. J.; Winger, B. E.; Loo, J. A. Org. Mass Spectrom. 1992, 27, 811.

20. Showstack, J. et al. New Engl. I. Met. 1989, 321, 1086.

21. Starzl, T. E.; Demetris, A. J.; Thiel, D. V. Nere Engl. I. Med. 1989, 321, 1092.

22. Oates, J. O.; Wood, A. J. J.; Kahan, B. B. Neal Engl. I. Med. 1989, 321, 1725

23. Schreiber, S. L. Science 1991, 251, 283.

24. Schreiber, S. L.; Albers, M. W.; Brown, E. J. Acc. Chem. Re's. 1993, 26, 412.

25. Rosen, M. K.; Schreiber, S. L. Angeze Che'm. Int. Ed. Engl. 1992, 31, 384.

26. (a) Standaert, R. F.; Galat, A.; Verdine, G. L.; Schreiber, S. L. Nature 1990, 346, 671; (b) Bierer, B. E.; Mattila, P. S.; Standaert, R. F.; Herzenberg, L. A.; Burakoff, S. J.; Crabtree, G.;
Schreiber, S. L. Proc. Natl. Acad. Sci. USA 1990, 87, 9231; (c) Harrison, R. K.; Stein, R. L. Bioch'mistry 1990, 29, 3813.

27. Olivares, J. A.; Nguyen, N. T.; Yonker, C. R.; Smith, R. D. Anal. Ch'm. 1987, 59, 1232.

28. Lee, E. D.; Muck, W.; Henion, J. D.; Covey, T. R. I. Chromatogr. 1988, 458, 313.

29. Mosely, M. A.; Detering, L. J.; Tomer, K. B.; Jorgenson, J. W Rapid Commun. Mass Spectrom. 1989, 3, 87.

30. Hallen, R. W.; Shumate, C. B.; Siems, W. F.; Tsuda, T.; Hill H. H., Jr. I. Chromatogr. 1989, 480, 233.

31. Smith, R. D.; Wahl, J. H.; Goodlett, D. R.; Hofstadler, S. A. Anal. Chem. 1993, 65, 574.

32. Loo, J. A.; Udseth, H. R.; Smith, R. D. Anal. Chem. 1989, 179 , 404 .

33. Nichols, W.; Zweigenbaum, J.; Garcia, F.; Johansson, M.; Henion., J. D. Liquid Chromatogr.-Gas Chromatogr. 1992, 10, 676.

34. Ocain, T. D.; Longhi, D.; Steffan, R. J.; Caccese, R. G.; Sehgal, S. N. Biochem. Biopliys. Re's. Commum. 1993, 192, 1340.

35. Harding, M. W.; Galat, A.; Uehling, D. E.; Schreiber, S. L. Nature 1989, 341, 758.

36. Gomez, F. A.; Avila, L. Z.; Chy, Y. H.; Whitesides, G. M. Anal. Cle'm. 1994, 66, 1785. 